\title{
Prevalence and burden of primary headache in Akaki textile mill workers, Ethiopia
}

\author{
Getahun Mengistu Takele · Redda Tekle Haimanot • \\ Paolo Martelletti
}

Received: 24 December 2007/Revised: 30 January 2008/ Accepted: 4 February 2008/Published online: 19 February 2008

(C) Springer-Verlag 2008

\begin{abstract}
Headache disorders are the most common complaints worldwide. Migraine, tension-type and cluster headaches account for majority of primary headaches and impose a substantial burden on the individual, family or society at large. The burden is immense on workers, women and children in terms of missing work and school days. There are few studies that show relatively lower prevalence of primary headaches in Africa as compared to Europe and America. There might be many reasons for this lower prevalence. The objective of this study is to determine the prevalence and burden of primary headaches among the Akaki textile factory workers, which may provide data for the local and international level toward the campaign of lifting the burden of headache worldwide. The overall 1-year prevalence of all types of primary headaches was found to be $16.4 \%$, and that of migraine was $6.2 \%$. The prevalence of migraine in females was $10.1 \%$ while it was $3.7 \%$ in males. The prevalence of tension-type headaches was found to be $9.8 \%$. This was $16.3 \%$ in females as compared to $5.7 \%$ in males. The burden of the primary headaches in terms of lost workdays, gross under recognition and absence of effective treatment is tremendous. In conclusion, the prevalence of primary headaches in the Akaki textile mill workers is significant, particularly in females, and the burden is massive, in a place of poverty and ignorance. We recommend the availability and administration of specific therapy to the factory workers
\end{abstract}

G. M. Takele $(\bowtie) \cdot$ R. Tekle Haimanot

School of Medicine, Department of Neurology, Addis Ababa

University, Addis Ababa, Ethiopia

e-mail: getahaau@yahoo.com

P. Martelletti

Master in Headache Medicine, 2nd School of Medicine

and Surgery, Sapienza University of Rome, Italy, Rome with primary headaches, and community based welldesigned study for the whole nation's rural and urban population.

\section{Introduction}

Headache is one among the most common medical complaints. Various forms of headache, properly called headache disorders, are among the most common disorders of the nervous system. They are pandemic and, in many cases, life-long conditions [1]. As many as 90\% of all primary headaches, including migraine, tension-type and cluster headache, fall under few categories. Recurrent headache disorders impose a substantial burden on headache sufferers, family and society [2]. Headache disorders are in the top ten, and possibly the top five, causes of disability worldwide [3]. Although the epidemiology of headache disorders is only partly documented, taken together, headache disorders are extraordinarily common. Population-based studies have mostly focused on migraine, which, although the most frequently studied, is not the most common headache disorder. Other types of headache, such as the more prevalent TTH and sub-types of the more disabling chronic daily headache, have received less attention [1].

The overall prevalence of migraine is estimated to be 12-16\% percent in North America and Europe [4]. Population-based studies are less available for other chronic headache syndromes, but tension-type headache seems to be more prevalent than migraine [5]. In developed countries, tension-type headache (TTH) alone affects two-thirds of adult males and over $80 \%$ of females. Extrapolation from figures for migraine prevalence and attack incidence 
suggests that 3,000 migraine attacks occur every day for each million of the general population. Less well recognized is the toll of chronic daily headache: up to one adult in 20 has headache, nearly every day or every day [1]. Migraine is more common in boys before the age of puberty but at the age of menarche the incidence of migraine increases in females, and migraine remains more common in women at all post-pubertal ages [2]. Both migraine and tension-type headaches affect women more often than men, while cluster headache is predominantly a disorder of men [5]. Migraine is more common in people from low-income households but less common in African Americans and Asians in the United States. These patterns of prevalence by race are also reflected in international studies, as migraine is most common in North America and Europe and less in Africa and Asia [2].

The recurrent headache disorders have an enormous impact on the individual and society. The individual impact is measured by the frequency and severity of attacks, while the societal burden is measured in terms of lost work and schooldays as well as healthcare utilization [2].

Few population-based studies exist for developing countries where limited funding and large and often rural populations, coupled with the low profile of headache disorders compared with other diseases, prevent the systematic collection of information [1]. There is a scanty data on the prevalence of primary headaches in sub-Saharan Africa in general and Ethiopia in particular. The prevalence of these headaches is very low as compared to Europe and North America. In 2004, the 1-year prevalence of headache from a door-to-door survey of rural south Tanzania was $23.1 \%$ (18.8\% males and $26.4 \%$ females). In this study, the 1-year prevalence of migraine was $5 \%$ with a male to female ratio of 1:2.8 and migraine without aura was $1.4 \%$ while migraine with aura was 3.6\% [6]. From a 1995 study done in Ethiopia, the 1-year prevalence of migraine was $3 \%$ (4.2\% females and $1.7 \%$ males) with a peak age specific rate in the fourth decade [7].

In Hong Kong, another third world country, the estimated prevalence of headaches in 2000 was $12.5 \%$ for migraine, $18.7 \%$ for tension-type headache and $6.0 \%$ for other types of headache [8].

In 2007, in the country of Georgia, Eastern Europe, the 1 - year prevalence of migraine was $8.6 \%$, tension-type headache was $20.4 \%$ and chronic daily headache was $5.4 \%$, two of whom were overusing acute headache medication [9]. In 2005, in an epidemilogic study in Florianopolis, Brazil, the 1-year prevalence of headache was $80.8 \%$, of migraine $22.1 \%$, of TTH $22.9 \%$, and of CDH $6.4 \%$ [10]. In Norway, out of 64,560 participants of a large populationbased study in 2000, the overall age-adjusted 1-year prevalence of headache was 38\% (46\% in women and $30 \%$ in men). The prevalence of migraine was $12 \%$ (16\% in women and $8 \%$ in men), and for non-migrainous headache $26 \%(30 \%$ in women and $22 \%$ in men). For frequent headache ( $>6$ days per month) and for chronic headache ( $>14$ days per month), the prevalence was 8 and $2 \%$, respectively [11].

The factors for such low prevalence in Africa in general and Ethiopia in particular might be the following:

1. Headache is under recognized and not diagnosed by many health practitioners in the African set up due to a number of reasons [12]:

I. Rural people have a great tolerance to pain hence do not report or seek medial attention.

II. Headache, even if persistent and recurrent, is often perceived as a trivial problem as there are more demanding and basic problems that are given priority.

III. Most rural headache sufferers come from low socioeconomic segment and are less educated.

IV. Most headache sufferers go for the traditional, religious and herbal medications.

2. It is not considered as a reason for medical consultation and even the sick people do not know headache as a medical condition

3. In the studies done so far, there were methodological problems, use of different classifications [like the one by the Ad Hoc Committee (AHC) on the Classification of Headache and the Headache Classification Committee of the International Headache Society (IHS), etc.] and absence of objective laboratory parameters for correlation of the headache data.

4. The presence of more than one type of primary headaches in a single patient, may have an impact on categorizing the patients even when the IHS criteria is used in the diagnosis of headache by less trained and less experienced health workers. Moreover, this is complicated by the absence of neurologists or headache specialists in most parts of Africa including Ethiopia.

5. Pain is more tolerated in the African culture than in Western countries. On top of this, diseases are perceived in the magico-religious context where traditional healing plays a big role.

6. Low incomes, poor infrastructures and inadequate health care coverage make the disease burden of headache different from that in the rich and developed nations.

7. There could be a genetic difference of Africans from that of Caucasians.

Migraine in Africans is not rare as reported in earlier reports. It is, however under recognized and accorded low priority. Its clinical manifestations in Africans are similar to those seen in other populations. It is an under-treated 
condition where only a low percentage of the sufferers receive specific treatment. The majority of migraine patients resort to herbal and traditional healers [3, 12].

In a world of limited resources for healthcare services and health related research, reliable data on the individual and societal impact of different disorders are crucial for a rational distribution of means [13]. Not only is headache painful, but headache disorders are also disabling [1]. Migraine associated disability remains substantial and pervasive [14]. Worldwide, according to the World Health Organization (WHO), migraine alone is 19th among all causes of years lived with disability (YLDs). Headache disorders impose recognizable burden on sufferers including, sometimes, substantial personal suffering, impaired quality of life and financial cost. Repeated headache attacks, and often the constant fear of the next one, damage family and social life as well as employment. For example, social activity and work capacity are reduced in almost all migraine sufferers and in $60 \%$ of TTH sufferers [1].

The disease burden and the costs incurred due to migraine are probably among the highest for the neurological disorders, and is probably high in poor countries as in the rich. For other headaches, reliable data on their impact are still scarce, but these disorders may be as important as migraine because they are more prevalent [13]. While those suffering from headache disorders bear much of the burden, they do not carry it all. Because headache disorders are most troublesome in the productive years (late teens to 50s), estimates of their financial cost to society, principally from lost working hours and reduced productivity, are massive. In the United Kingdom, for example, some 25 million working or school days are lost every year because of migraine alone. TTH, less disabling but more common, and chronic daily headache, less common but more disabling, together cause losses which are almost certainly of at least similar magnitude [1]. In a 2002 study of Italy, among young Italian patients, quality of life was compromised in primary headache and was significantly lower in psychosocial, physical and social functioning [15].

Headache rarely signals serious underlying illness; its public-health importance lies in its causal association with these personal and societal burdens of pain, disability, damaged quality of life and financial cost [1]. The societal impact of headaches is usually measured in economic terms. Direct costs consist primarily of health care utilization. Indirect costs include missed work (i.e., absenteeism) and reduced productivity while at work (i.e., presenteeism) due to headache [2].

Headache is high among causes of consulting medical practitioners. A survey of neurologists found that up to one-third of all their patients consulted because of headache, more than for any other complaint [1]. The direct costs of diagnosing and treating primary headaches are far less than the costs of productivity losses due to headache attacks. As a consequence, improving health care delivery for primary headaches could be cost effective from a societal perspective [2]. The common headache disorders require no special investigation and they are diagnosed and managed with skills that should be generally available to physicians. In theory, therefore, most headaches can be optimally managed in primary care. There are barriers to effective care of these primary headache disorders. These barriers vary throughout the world, but may be classified as clinical, social or political/economic [1]. For the developed nations, there are many cost-effective, efficacious treatments available, but these are limited, unavailable or unaffordable in the developing nations [2, 7, 12].

Headache ought to be a public-health concern. Yet there is good evidence that very large numbers of people troubled by headache do not receive effective care. For example, in representative samples of the general populations of the United States of America and the United Kingdom, only half of those identified with migraine had seen a doctor for headache-related reasons in the previous 12 months, and only two-thirds had been correctly diagnosed. Most were solely reliant on over-the-counter medications [1]. Yet the reality is that, for the vast majority of those whose quality of life is spoiled by headache, effective treatment requires no expensive equipments, tests or specialists. The essential components of effective medical management are awareness of the problem, correct recognition and diagnosis, avoidance of mismanagement, appropriate lifestyle modification and informed use of costeffective pharmaceutical remedies [3].

\section{Objective}

The general objective is to determine the prevalence and burden of primary headaches among the textile mills workers in Addis Ababa, Ethiopia

Specific objectives are:

1. To determine the magnitude and prevalence of primary headaches in the textile mills' workers

2. To see the burden of these headaches among the sufferers.

3. To know the missing working days and hence assess the impact of primary headaches on the productivity in particular and on economy in general.

4. To assess the care provided to the headache patients (workers) versus the over the counter use and or misuse of drugs for headache.

5. To generate data on headache prevalence and burden for use by the national and international policy makers on health care. 


\section{Patients and methods}

The study population included all workers in the Akaki textile mill. This cross-sectional prevalence study was conducted among the Akaki textile mill workers from 1 November 2007 to 28 November 2007. It included the entire workers employed by the factory. It is located in Kality, Akaki sub-city of Addis Ababa, about $25 \mathrm{~km}$ east of the center. It has 1,300 workers and is about 52 years old, being one of the oldest factories of the country.

Data collection was done by the investigator (PI), three nurses and a medical doctor of the factory after training and orientation on primary headaches. Prepared and pretested questionnaires were used. The questionnaire was divided into two parts, the first part was on the demographic and personal aspects and the second part dealt with the specific details of headache. Cases with positive history of headache were interviewed and examined by the physician trained in headache medicine, internal medicine and neurology. Subjects were diagnosed in accordance to the most frequent type of headache experienced in the last 1 year, using HIS criteria [16]. Migraine and tension-type headache were diagnosed when all criteria were fulfilled. The diagnosis of probable was made when all but one criterion were fulfilled. Chronic headache was diagnosed when the frequency of headache pain was $\geq 180$ days per year, based on a question about the frequency of headache.

Data quality was checked and crosschecked by the PI. The collected data were processed with a computer EpiInfo version 2002 and SPSS 11.0 software packages. Chisquare, OR, $P$ value and $95 \%$ Confidence interval were used for analysis.

\section{Ethical consideration}

The proposal was submitted to the Faculty Research and Publication Committee (FRPC) of Addis Ababa University Faculty of Medicine for necessary processes as per rules and regulations. It was approved on 5 October 2007. Institutional ethical clearance was obtained. Informed consent was obtained from the study participants.

Dissemination of results

The results and outputs of the study will be published in the national or international Journals and copies will be given to MOH, AAU-RPO, Faculty of Medicine Library and NGOs

\section{Results}

Of the 1,300 employees of the Akaki textile mill on job at the time of the interview, 195 did not want to participate in the interview. Out of $1,105(85 \%)$ interviewed, 681 $(61.6 \%)$ were males and $424(38.4 \%)$ were females. The age ranged from 25 to 77 years with mean of $46.9 \pm 7.5$. There were two workers beyond the age of 65 , working as a cleaner and a guard. Out of the total, $590(53.4 \%)$ were in the age range of $45-54$ years (Table 1). Of the total study population, $866(78.4 \%)$ were married, of which $260(30 \%)$ were females. The divorce rate was $9.0 \%$ (99), of which 87 $(87.9 \%)$ were females. About $6.7 \%$ (74) were widowed of which widows accounted for $79.7 \%$ (59) while widowers were $20.3 \% \quad(15) \quad\left(x^{2}=185.1, \quad\right.$ df $\left.=3, \quad P=0.00000\right)$ (Fig. 1).

Illiteracy rate (did not read or write) of the study population was $9.9 \%$ (220), of which $161(73.2 \%)$ were females; on the other hand, among $8.5 \%$ (94) who had tertiary education $75.5 \%$ (71) were males $\left(x^{2}=154.6\right.$, df $=3, P=0.0000$ ) (Fig. 2).

Lifetime prevalence of all sorts of headaches was $96.1 \%, 98.6 \%$ in females versus $95.9 \%$ in males (adjusted $\mathrm{OR}=2.3,95 \%$ confidence interval of $0.90-5.64)$. Oneyear prevalence of all types headaches was $73.2 \%$, in females $79.2 \%$ compared $69.5 \%$ in males $(\mathrm{OR}=1.20$, 95\% CI $=0.90-1.63$ ) (Table 2).

The overall 1-year prevalence of all types of primary headaches was found to be $16.4 \%(181 / 1,105)$. Out of these 181 cases, $114(63 \%)$ with primary headache were females making a prevalence of $26.9 \%$ in the females while it was $9.8 \%$ in males. This is statistically significant (adjusted $\mathrm{OR}=3.13,95 \%$ confidence interval of 2.22-4.41, $P=0.000$ ). The age specific prevalence was $18.0 \%$ in the age group of 45-54 years (Tables 2, 4).

According to the International Headache Society criteria, 68 workers were found to have migraine giving a prevalence rate of $6.2 \%$. The prevalence of migraine in females was $10.1 \%$ while it was $3.7 \%$ in males (adjusted

Table 1 The age and sex distribution of the study population Akaki textile mill, Ethiopia, 2007

\begin{tabular}{|c|c|c|c|c|c|c|}
\hline \multirow[t]{2}{*}{ Age (years) } & \multicolumn{2}{|c|}{ Male } & \multicolumn{2}{|c|}{ Female } & \multicolumn{2}{|l|}{ Total } \\
\hline & No & $\%$ & No & $\%$ & No & $\%$ \\
\hline $25-34$ & 33 & 4.8 & 27 & 6.4 & 60 & 5.4 \\
\hline $35-44$ & 176 & 25.8 & 107 & 25.2 & 283 & 25.6 \\
\hline $45-54$ & 357 & 52.4 & 233 & 55.0 & 590 & 53.4 \\
\hline $55-64$ & 113 & 16.6 & 57 & 13.4 & 170 & 15.4 \\
\hline $65+$ & 2 & 0.3 & 0 & 0 & 2 & 0.2 \\
\hline Total & 681 & 61.6 & 424 & 38.4 & 1,105 & 100.0 \\
\hline
\end{tabular}


Fig. 1 Marital status of study population by gender Akaki textile mill, Ethiopia, 2007

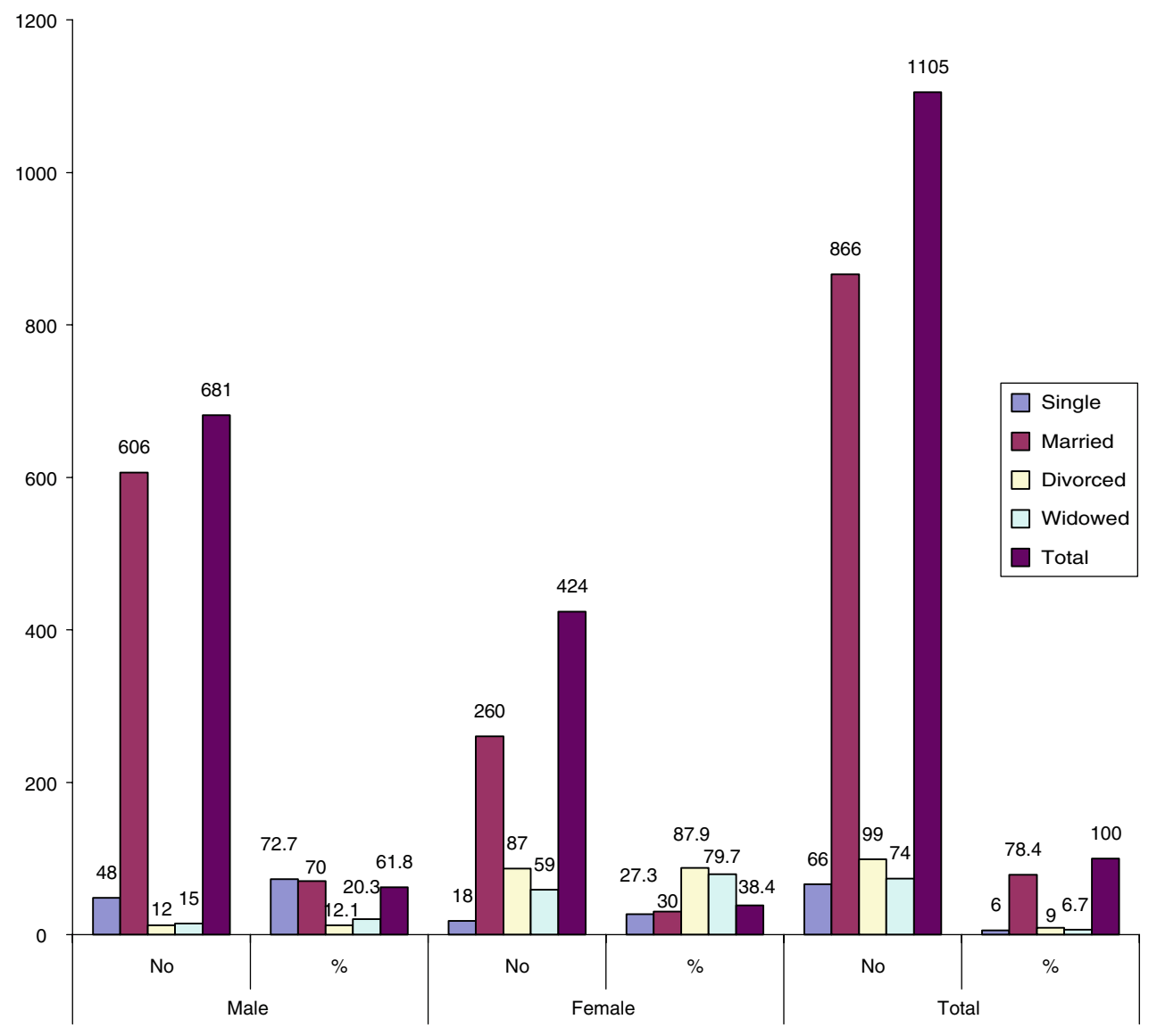

$\mathrm{OR}=3.23,95 \% \mathrm{CI}=2.11-4.94, P=0.000)$. The age specific prevalence was $7.3 \%$ in the age range of 4554 years. The over all prevalence of migraine without aura was $51(4.6 \%)$ making $75 \%$ of the migraine patients. This was 8.5 (36) in females and 2.2\% (15) in males (adjusted $\mathrm{OR}=4.63,95 \% 2.50-8.58, P=0.000)$. The prevalence of migraine with aura was found to be $1.4 \%$ and that of probable migraine was found to be $0.1 \%$ (Tables 3,4 ).

The over all prevalence of tension-type headaches was found to be $9.8 \%(108 / 1,105)$. This was $16.3 \%$ in females as compared to $5.7 \%$ in males (adjusted $\mathrm{OR}=3.14$, $95 \% \mathrm{CI}=1.87-5.28, P=0.000)$. The age specific prevalence was $13.3 \%$ in the age group of 25-34 years. Frequent episodic tension-type headache was found to be $4.3 \%$, with $7.1 \%$ in females and $2.5 \%$ in males (adjusted OR $=3.45$, $95 \%$ CI of $1.87-6.35, P=0.000)$. The prevalence of infrequent episodic tension headache was 3.5 , and $5.2 \%$ in females and $2.5 \%$ in males (adjusted OR $=2.45,95 \%$ $\mathrm{CI}=1.28-4.70, P=0.007)$. Chronic tension-type headache was found to be 1.6 and $3.5 \%$ in females and $0.4 \%$ in males (adjusted $\mathrm{OR}=9.77, \quad 95 \% \quad \mathrm{CI}=2.81-34.00$, $P=0.000)$. Probable tension-type headache was found to be $0.4 \%$ (Tables 3,4 ).

Cluster headache and other trigeminal autonomic cephalalgias were found in five $(0.45 \%)$ individuals.
Table 5 shows the prevalence of headache versus marital status. The widowed ones have the significant higher proportion of all types of headaches followed by the divorced.

Table 6 shows the prevalence of headaches in educational categories. The general trend of reciprocal relationship of headache and educational levels was found to be evident but this is not significant statistically when confounders are controlled.

Tables 7 and 8 show the proportion of missing workdays in primary headaches during attacks. Out of 181 workers with primary headaches, $63(34.8 \%)$ miss working days due to headache attacks. This was $60.3 \%$ in migraine and $20.4 \%$ in tension-type headaches.

Table 9 shows the use of ant-pain medications for attacks of headache. Only one patient, who has migraine with aura, ever used ergot preparation from the specific medications, the only available specific medication in Ethiopia. The most widely used over the counter medicine was acetaminophen tablets. Out of 181 workers with primary headaches, $80.1 \%$ used ant-pains intermittently or during every attack. This was $97.1 \%$ in migraine and $70.4 \%$ in tension headache. The reasons given for those who did not use medicines were: no lasting remedy or response at all, use of alternatives like traditional medicine and holy water and fear of abuse of drugs. 
Fig. 2 Educational status of study population by gender, Akaki textile mill, Ethiopia, 2007

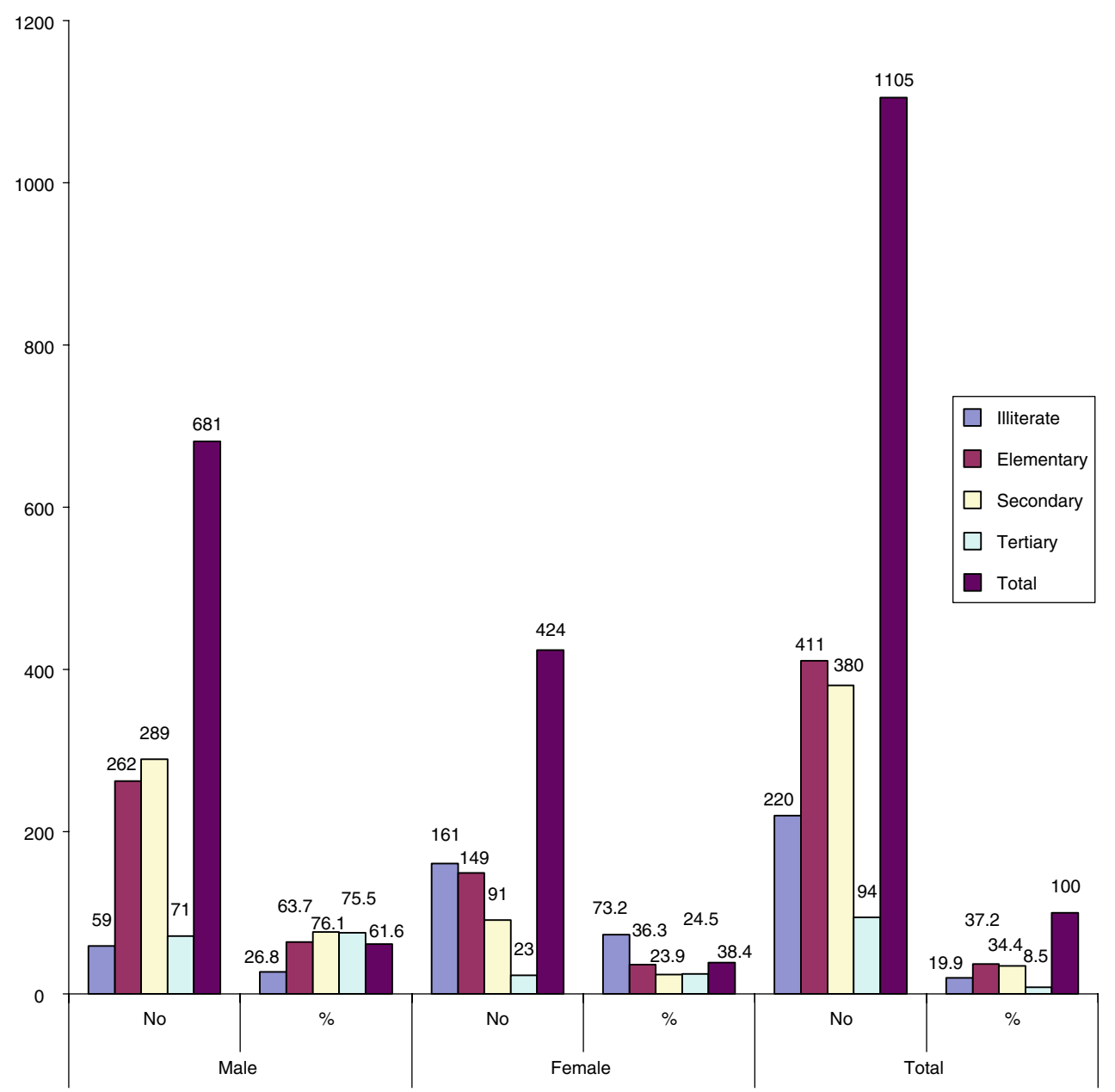

Average age of onset for primary headaches was $25.7 \pm 12.4$ years, where as it was $21.9 \pm 11$ for migraine and $27.7 \pm 12.2$ for tension-type headaches. Out of the average $27.3 \pm 7.7$ years spent on job in the textile mills, $21.9 \pm 12.4$ years were with episodes of headache. These workers on average have $13.77 \pm 15.5$ days of missing work per year. This was $15.6 \pm 15.4$ days for migraine and $11.2 \pm 15.6$ days per year for tension-type of headaches. Of the mean $47.3 \pm 7.1$ years of life, $21.9 \pm 12.4$ were spent with intermittent episodes of headache. It was $26.8 \pm 15.5$ years for migraine and $19.24 \pm 11.8$ years for tension-type headache (Table 10).

\section{Discussion}

Lifetime prevalence of all sorts of headaches in this study is more than $96.0 \%$ which is in accordance to the studies done elsewhere [17]. The 1-year prevalence of all kinds of headache was $73 \%$. This is slightly lower than the 1-year prevalence of the 2005 study of Florianopolis in Brazil, which was $80.8 \%$ [10].

The 1-year prevalence of migraine, $6.2 \%$ in this study is lower than the 2007 prevalence of migraine and probable migraine of Georgia, which was $21.5 \%$ where as it was closer to the definite migraine prevalence of $8.5 \%$ [9]. The

Table 2 Prevalence of headache in the study population, Akaki textile mill, Ethiopia, 2007

\begin{tabular}{|c|c|c|c|c|c|c|c|c|c|}
\hline \multirow[t]{2}{*}{ Category } & \multicolumn{2}{|c|}{ Female } & \multicolumn{2}{|c|}{ Male } & \multicolumn{2}{|l|}{ Total } & \multirow{2}{*}{$\begin{array}{l}\text { Adusted } \\
\text { odds ratio }\end{array}$} & \multirow{2}{*}{$\begin{array}{l}95 \% \text { Confidence } \\
\text { interval }\end{array}$} & \multirow[t]{2}{*}{$P$ value } \\
\hline & No & $\%$ & No & $\%$ & No & $\%$ & & & \\
\hline Lifetime headache prevalence & 418 & 98.8 & 653 & 95.9 & 1071 & 96.9 & 2.30 & $0.90-5.64$ & 0.083 \\
\hline One-year headache prevalence & 336 & 79.2 & 473 & 69.5 & 809 & 73.2 & 1.20 & $0.90-1.63$ & 0.247 \\
\hline Primary headaches prevalence & 114 & 26.9 & 67 & 9.8 & 181 & 16.4 & 3.13 & $2.22-4.41$ & 0.000 \\
\hline Total population & 424 & 38.4 & 681 & 61.6 & 1105 & 100.0 & & & \\
\hline
\end{tabular}


Table 3 Migraine and tension headache categories by sex, Akaki textile mill, Ethiopia, 2007

\begin{tabular}{|c|c|c|c|c|c|c|c|c|c|}
\hline \multirow[t]{2}{*}{ Category } & \multicolumn{2}{|c|}{ Female } & \multicolumn{2}{|c|}{ Male } & \multicolumn{2}{|c|}{ Total } & \multirow{2}{*}{$\begin{array}{l}\text { Adjusted } \\
\text { odds ratio }\end{array}$} & \multirow{2}{*}{$\begin{array}{l}95 \% \text { Confidence } \\
\text { interval }\end{array}$} & \multirow[t]{2}{*}{$P$ value } \\
\hline & No & $\%$ & No & $\%$ & No & $\%$ & & & \\
\hline Migraine without aura & 36 & 8.5 & 15 & 2.2 & 51 & 4.6 & 4.63 & $2.60-8.60$ & 0.000 \\
\hline Migraine with aura & 6 & 1.4 & 10 & 1.5 & 16 & 1.4 & 0.96 & $0.35-2.67$ & 0.85 \\
\hline Probable migraine & 1 & 0.1 & 0 & 0 & 1 & 0.1 & & & \\
\hline subtotal & 43 & 10.1 & 25 & 3.7 & 68 & 6.2 & 3.23 & $2.11-4.94$ & 0.000 \\
\hline Infrequent episodic tension type & 22 & 5.2 & 17 & 2.5 & 39 & 3.5 & 2.45 & $1.28-4.70$ & 0.007 \\
\hline Frequent episodic tension type & 30 & 7.1 & 17 & 2.5 & 47 & 4.3 & 3.45 & $1.87-6.45$ & 0.000 \\
\hline Probable tension type & 2 & 0.5 & 2 & 0.3 & 4 & 0.4 & 1.61 & $0.23-11.47$ & 0.97 \\
\hline Chronic tension type & 15 & 3.5 & 3 & 0.4 & 18 & 1.6 & 9.77 & $2.81-34.00$ & 0.000 \\
\hline subtotal & 69 & 16.3 & 39 & 5.7 & 108 & 9.8 & 3.14 & $1.87-5.28$ & 0.000 \\
\hline
\end{tabular}

Table 4 Prevalence headaches by age category, Akaki textile mill, Ethiopia, 2007

\begin{tabular}{lcccccccc}
\hline $\begin{array}{l}\text { Age } \\
\text { category }\end{array}$ & $\begin{array}{l}\text { All types of } \\
\text { tension } \\
\text { headaches }\end{array}$ & & & $\begin{array}{l}\text { All types of } \\
\text { migraine } \\
\text { headaches }\end{array}$ & & \multicolumn{2}{l}{$\begin{array}{l}\text { All types of } \\
\text { primary } \\
\text { headaches }\end{array}$} \\
\cline { 2 - 3 } & Number & $\%$ & & Number & $\%$ & & Number & $\%$ \\
\hline $25-34$ & 8 & 13.3 & 2 & 3.3 & 10 & 16.7 \\
$35-44$ & 26 & 9.2 & 11 & 3.9 & 38 & 13.4 \\
$45-54$ & 59 & 10.0 & 43 & 7.3 & 106 & 18.0 \\
$55-64$ & 15 & 8.8 & 12 & 7.1 & 27 & 15.9 \\
$65+$ & 0 & 0 & 0 & 0 & 0 & 0 \\
Total & 108 & 9.8 & 68 & 6.2 & 181 & 16.4 \\
\hline
\end{tabular}

prevalence in this study is within the WHO estimate of 3-7\% in Africa according to the community- based studies [1] but much lower than the global data of $11 \%$ [18]. This study showed similar prevalence of migraine to the doorto-door study done in 2004 in rural area of southern Tanzania where the overall 1-year prevalence was 5.0\% [6]. In a study done in 1995, in the rural Ethiopian community, 1-year prevalence of migraine, $3.0 \%$ was lower than the figure in this study [7]. The reasons for such difference might be that the current study is in an urban setup where people can report and perceive headache as an illness and this study was done in factory employees where as the previous one was in a rural community. Almost similar prevalence of $4.7 \%$ was found in a 2000 study from Hong Kong [8]. This study showed much lower prevalence of migraine as compared to the 2005 study of Florianopolis in Brazil, which was $22.1 \%$ [10]. In this study, migraine without aura accounted for $75 \%$ of the cases with a prevalence of $4.6 \%$ and preponderance in females was statistically significant. The low prevalence of migraine with aura $1.4 \%$ accounting for $24 \%$ of cases with migraine is in agreement with the previous reports from Africa in general and Ethiopia in particular [7, 12].

The 1-year overall prevalence of tension-type headache, $9.8 \%$ in this study is lower than the reported prevalence of $20.4 \%$ from Georgia [9] and very much lower than the 2007 global estimate of $42 \%$ [18]. This is much higher than the $1.7 \%$ reported by WHO in some African community based studies [1]. In a 2000 study from Hong Kong, the overall prevalence of tension-type headache of $26.9 \%$ was much higher than the present study [8]. In our study, the prevalence of tension-headache was much lower than the 2005 study of Florianopolis in Brazil, which was $22.9 \%$ [10]. Chronic tension-type headache in this study found to

Table 5 Marital status and prevalence of headache, Akaki textile mill, Ethiopia, 2007

\begin{tabular}{|c|c|c|c|c|c|c|c|c|c|c|c|c|}
\hline \multirow{2}{*}{$\begin{array}{l}\text { Status } \\
\text { Type }\end{array}$} & \multicolumn{2}{|c|}{ Single } & \multicolumn{2}{|c|}{ Married } & \multicolumn{2}{|c|}{ Divorced } & \multicolumn{2}{|c|}{ Widowed } & \multirow{2}{*}{$\begin{array}{l}\text { Total } \\
\text { No }\end{array}$} & \multirow[t]{2}{*}{$x^{2}$} & \multirow[t]{2}{*}{$d f$} & \multirow[t]{2}{*}{$P$} \\
\hline & No & $\%$ & No & $\%$ & No & $\%$ & No & $\%$ & & & & \\
\hline Primary & 9 & 13.6 & 122 & 14.1 & 26 & 26.3 & 24 & 32.4 & 181 & 24.67 & 3 & 0.0000 \\
\hline Tension & 7 & 10.6 & 74 & 8.5 & 13 & 13.1 & 14 & 18.9 & 108 & 9.8 & 3 & 0.02 \\
\hline Migraine & 2 & 3.0 & 43 & 5.0 & 13 & 13.1 & 10 & 13.5 & 68 & 18.5 & 3 & 0.0003 \\
\hline Migraine without aura & 2 & 3.0 & 28 & 3.2 & 12 & 12.1 & 9 & 12.2 & 51 & 26.4 & 3 & 0.0000 \\
\hline $\begin{array}{l}\text { Life time headache } \\
\text { prevalence }\end{array}$ & 63 & 95.5 & 837 & 96.7 & 97 & 98.0 & 74 & 100.0 & 1,071 & 3.4 & 3 & 0.3 \\
\hline $\begin{array}{l}\text { One year headache } \\
\text { prevalence }\end{array}$ & 52 & 78.8 & 624 & 72.1 & 71 & 71.7 & 63 & 85.1 & 810 & 14.3 & 3 & 0.0025 \\
\hline
\end{tabular}


Table 6 Educational status and prevalence of headache, Akaki textile mill, Ethiopia, 2007

\begin{tabular}{|c|c|c|c|c|c|c|c|c|c|c|c|c|}
\hline \multirow{2}{*}{$\begin{array}{l}\text { Status } \\
\text { Type }\end{array}$} & \multicolumn{2}{|c|}{ Illiterate } & \multicolumn{2}{|c|}{ Elementary } & \multicolumn{2}{|c|}{ Secondary } & \multicolumn{2}{|c|}{ Tertiary } & \multirow{2}{*}{$\begin{array}{l}\text { Total } \\
\text { No }\end{array}$} & \multirow[t]{2}{*}{$x^{2}$} & \multirow[t]{2}{*}{$d f$} & \multirow[t]{2}{*}{$P$} \\
\hline & No & $\%$ & No & $\%$ & No & $\%$ & No & $\%$ & & & & \\
\hline All primary & 55 & 25.0 & 69 & 16.8 & 47 & 12.4 & 10 & 10.6 & 181 & 18.7 & 3 & 0.003 \\
\hline Tension & 32 & 14.5 & 39 & 9.5 & 29 & 7.6 & 8 & 8.5 & 108 & 7.9 & 3 & 0.049 \\
\hline Migraine & 22 & 10.0 & 28 & 6.8 & 16 & 4.2 & 2 & 2.1 & 68 & 11.1 & 3 & 0.011 \\
\hline Migraine without aura & 20 & 9.1 & 21 & 5.1 & 9 & 2.4 & 1 & 1.1 & 51 & 17.3 & 3 & 0.0006 \\
\hline $\begin{array}{l}\text { Lifetime headache } \\
\text { prevalence }\end{array}$ & 219 & 99.5 & 406 & 98.8 & 360 & 94.7 & 86 & 91.5 & 1,071 & 25.2 & 3 & 0.0000 \\
\hline $\begin{array}{l}\text { One-year headache } \\
\text { prevalence }\end{array}$ & 180 & 81.8 & 298 & 72.5 & 259 & 68.2 & 73 & 77.7 & 810 & 14.3 & 3 & 0.0025 \\
\hline
\end{tabular}

Table 7 Primary headaches versus missing working days, Akaki textile mill, Ethiopia, 2007

\begin{tabular}{|c|c|c|c|c|c|c|}
\hline \multirow[t]{2}{*}{ Category } & \multicolumn{2}{|c|}{ Missing work days } & \multirow{2}{*}{$\begin{array}{l}\text { Crude } \\
\text { odds ratio }\end{array}$} & \multirow{2}{*}{$\begin{array}{l}95 \% \\
\text { confidence } \\
\text { interval }\end{array}$} & \multirow[t]{2}{*}{$X^{2}$} & \multirow[t]{2}{*}{$P$ value } \\
\hline & No & $\%$ & & & & \\
\hline Migraine & $41 / 68$ & 60.3 & 6.3 & $3.2-12.3$ & 29.4 & 0.000001 \\
\hline Migraine without aura & $29 / 51$ & 56.9 & 3.7 & $1.9-7.3$ & 13.9 & 0.0002 \\
\hline Migraine with aura & $11 / 16$ & 68.8 & 4.8 & $1.6-14.5$ & 7.3 & 0.007 \\
\hline Tension type & $22 / 108$ & 20.4 & 0.2 & $0.10-0.40$ & 23 & 0.000003 \\
\hline Infrequent episodic tension type & 7 & 17.9 & 0.34 & $012-0.81$ & 5.3 & 0.02 \\
\hline Frequent episodic tension type & 11 & 23.4 & 0.48 & $0.22-1.02$ & 3.0 & 0.08 \\
\hline Chronic tension type & 4 & 22.2 & 4.98 & $1.59-15.59$ & 6.43 & 0.011 \\
\hline All primary headaches & $63 / 181$ & 34.8 & 0.14 & $0.05-0.41$ & 14.5 & 0.00014 \\
\hline
\end{tabular}

\begin{tabular}{lrrrrl}
\hline Category & Number & $\%$ & $\begin{array}{l}\text { Adjusted } \\
\text { odds ratio }\end{array}$ & $\begin{array}{l}95 \% \\
\text { confidence } \\
\text { interval }\end{array}$ & $\begin{array}{l}P \\
\text { value }\end{array}$ \\
\hline Migraine headaches & 41 & 60.3 & & & \\
Migraine without aura & 29 & 56.9 & 383.84 & $108.46-1358.43$ & 0.000 \\
Migraine with aura & 11 & 68.8 & 624.99 & $131.27-2975.61$ & 0.000 \\
Tension-type headaches & 22 & 20.4 & & & $14.11-244.47$ \\
Infrequent episodic tension type & 7 & 17.9 & 58.73 & 0.000 \\
Frequent episodic tension type & 11 & 23.4 & 95.45 & $25.52-356.95$ & 0.000 \\
Chronic tension type & 4 & 22.2 & 89.25 & $18.26-436.36$ & 0.000 \\
All primary headaches & 63 & 34.8 & & & \\
\hline
\end{tabular}

Table 8 Primary headaches versus missing of workdays, Akaki textile mill, Ethiopia, 2007 be $1.6 \%$ is in accordance to the WHO figure of $1-3 \%$ in adults and previous report from rural Ethiopia, which was $1.7 \%[1,7,12]$. The 1-year prevalence of chronic tensiontype headache, which is one of the most disabling headache syndromes, in our study is $3.5 \%$ in females and $0.4 \%$ in males. This gender difference was statistically significant.

Cluster headache is extremely rare in Africa as reported previously, as well as in this study $[1,7,12]$.

Both migraine and tension headache have an enormous burden and impact on the individual family, society and on the nation. This burden is serious in developing countries like Ethiopia where the resources are meager, ignorance and poverty are overwhelming, and infrastructures for healthcare systems are scanty. The cumulative impact over time with a compromised quality of life was enormous on individuals. In this study, cases with primary headache and migraine each lived 21.9 years on average with intermittent attacks of headache while this was more than 19 years for tension headache. The majority of cases with migraine have severe or moderate attacks of headache, photophobia, phonophobia and nausea or vomiting. 

versus use of medicine (antpain), Akaki textile mill, Ethiopia, 2007
Table 9 Primary headaches

\begin{tabular}{|c|c|c|c|c|c|}
\hline \multirow[t]{2}{*}{ Category } & \multicolumn{2}{|c|}{ Medicine use } & \multirow{2}{*}{$\begin{array}{l}\text { Adjusted } \\
\text { odds ratio }\end{array}$} & \multirow{2}{*}{$\begin{array}{l}95 \% \\
\text { confidence } \\
\text { interval }\end{array}$} & \multirow[t]{2}{*}{$P$-value } \\
\hline & No & $\%$ & & & \\
\hline Migraine & $66 / 68$ & 97.1 & $3,349.47$ & $733.4-15297.5$ & 0.000 \\
\hline Migraine without aura & 51 & 100.0 & $1,196.39$ & $0.000-5.6 \mathrm{E}+17$ & 0.307 \\
\hline Migraine with aura & 14 & 87.5 & 530.86 & $122.37-2303.03$ & 0.000 \\
\hline Tension type & $76 / 108$ & 70.4 & 367.98 & $126.64-1069.24$ & 0.000 \\
\hline Infrequent ETTH & 28 & 71.8 & 325.75 & $117.23-905.16$ & 0.000 \\
\hline Frequent ETTH & 36 & 76.6 & 422.27 & $154.43-1154.68$ & 0.000 \\
\hline Chronic TTH & 12 & 66.7 & 265.43 & $77.57-908.23$ & 0.000 \\
\hline All primary headaches & $145 / 181$ & 80.1 & $2,473.44$ & $336.34-18189.49$ & 0.000 \\
\hline
\end{tabular}

Table 10 Primary headaches and the burden, Akaki textile mill, Ethiopia, 2007

\begin{tabular}{lllr}
\hline Category & Mean value & SD & Range \\
\hline Mean age in years & 47.3 & 7.1 & $30-60$ \\
Mean years on work & 27.3 & 7.7 & $5-47$ \\
Means years lived with primary headaches & 21.9 & 12.4 & $1-50$ \\
Mean age in years at onset of all primary headaches & 25.7 & 12.2 & $5-55$ \\
Mean age in years at onset of tension-type headache & 27.7 & 12.2 & $5-55$ \\
Mean age in years at onset of migraine headache & 21.9 & 11 & $6-53$ \\
Mean years lived with tension-type headaches & 19.24 & 11.77 & $1-48$ \\
Mean years lived with migraine headaches & 26.8 & 11.78 & $2-50$ \\
Mean days of missing work due to all primary headaches per year & 13.77 & 15.5 & $1-60$ \\
Mean days of missing work due to migraine headaches per year & 15.61 & 15.4 & $1-60$ \\
Mean days of missing work due to tension-type headaches per year & 11.17 & 15.57 & $2-60$ \\
\hline
\end{tabular}

Although the 1-year prevalence of primary headaches above $16 \%$ in this study is much lower than the global estimate $46 \%$ and that of Africa $21 \%$ [18], only one case of migraine with aura was ever treated with available specific medication of ergot preparation in the past. This shows how serious is the under recognition and under treatment of headaches in the capital city of Ethiopia, Addis Ababa. To complicate the matter, all sufferers in this study did not know that effective treatment exists and the care givers did not diagnose as well treat them.

Many migraine sufferers miss work because of their headaches, and reduced productivity as a result of working during the migraine attack is common [2].

In our study, more than $60 \%$ with migraine and above $20 \%$ with tension headache missed working days and almost all with migraine as well as more than half with tension headache have a reduced work capacity during attacks. This is in agreement with the WHO report [1, 19]. In this study, $34.8 \%$ of cases with primary headache had on average 13.77 lost work days per year and this was higher in migraine, about 16 lost working days, and least in tension type, 11 lost working days. This is almost in agreement with the 1995 study from Dares Salaam, Tanzania, which was 11.3 lost workdays per year [20]. The economic impact on workers and their families as well as on the nation is massive especially for a developing country like Ethiopia, where poverty, ignorance and malnutrition are rampant.

In conclusion, the prevalence of primary headaches in the Akaki textile mill is significant, particularly in females, and the burden is massive, in a place of poverty and ignorance.

We recommend the availability and administration of specific therapy to the factory workers with primary headaches, and community based well-designed study for the whole nation's rural and urban population, as suggested in the WHO's Aids for management of common headache disorders in primary care [21].

Acknowledgments This epidemiological work represents the final dissertation held at the Master in Headache Medicine by Dr. Getahun Mengistu Takele, during the Academic year 2006-2007 at Sapienza University of Rome. Dr. Mengistu's scholarship has been granted by Sapienza University (0010959-2.2.4.1.40.2 to the author P.M.) in favor of the WHO's Global Campaign Lifting the Burden. The author G.M.T. is indebted to Dr. Worash Getaneh, geologist from Addis Ababa University, Department of Earth and Environmental Sciences for his ever-unreserved effort in accessing the Internet and encouraging the first author. He did allow his office and personal computer use day and night and sacrificed his time despite many commitments. We thank also Dr. Mihela Zebenigus, neurologist in the Department of Neurology of Addis Ababa University for her continuous support. 
Finally we are grateful to the participants and management of Akaki textile without which this study would not have been successful.

Conflict of interest None.

\section{References}

1. World Health Organization (2004) Headache Disorders. Fact sheet N`277, March 2004. Accessed 28 June 2007

2. Munsat TL, Mancall EL, DesLauriers MP (1994) The AAN launches a new education program: CONTINUUM lifelong learning in neurology. Neurology 44:771-772

3. Steiner TJ (2005) Lifting the burden: the global campaign to reduce the burden of headache worldwide. J Headache Pain 6:373-377

4. Rasmussen BK (1995) Epidemiology of migraine. Biomed Pharmacother 49:452-455

5. Rasmussen BK, Jensen R, Schroll M, Olesen J (1991) Epidemiology of headache in a general population-a prevalence study. J Clin Epidemiol 44:1147-1157

6. Dent W, Spiss HK, Helbok R, Matuja WBP, Sheunemann S, Schmutzard E (2004) Prevalence of migraine in a rural area in South Tanzania: a door-to-door survey. Cephalalgia 24:960-966

7. Tekle Haimanot R, Seraw B, Forsgren L, Ekbom K, Ekstedt J (1995) Migraine, chronic tension type headache and cluster headache in an Ethiopian rural community. Cephalalgia 15:482488

8. Cheung Raymond TF (2000) Prevalence of migraine, tension type headache and other headaches in Hong Kong. Headache 40:473-479

9. Katsarava Z, Kukava M, Mirvelashvili E, Tavadze A, Dzagnidze A, Djibuti M, Steiner TJ (2007) A pilot methodological validation study for a population-based survey of the prevalences of migraine, tension type headache and chronic daily headache in the country of Georgia. J Headache Pain 8:77-82

10. Queiroz LP, Barea LM, Blank N (2005) An epidemiological study of headache in Florianopolis, Brazil. Cephalalgia 26:122127

11. Hagen K, Zwart JA, Vatten L, Stovner LJ, Bovim G (2000) Prevalence of migraine and non-migrainous headache-headHUNT, a large population-based study. Cephalalgia 20:900-906

12. Tekle Haimanot R (2003) Burden of headache in Africa. J Headache Pain 4:S47-S54

13. Stovner LJ, Hagen K (2006) Prevalence, burden, and cost of headache disorders. Curr Opin Neurol 19:281-285

14. Lipton RB, Stewart WF, Diamond S, Diamond ML, Reed M (2001) Prevalence and burden of migraine in the United States: data from the American Migraine Study II. Headache 41:646-657

15. Nodari E, Battistella A, Naccarella C, Vidi M (2002) Quality of life in young Italian patients with primary headache. Headache 42:268-274

16. Headache Classification Subcommittee of the International Headache Society (2004) The international classification of headache disorders, 2 nd edn. Cephalalgia 24:1-160

17. Steiner TJ (2004) Lifting the burden: the global campaign against headache. Lancet Neurol 3:204-205

18. Stovner LJ, Hagen K, Jensen R, Katsarava Z, Lipton RB, Scher AI, Steiner TJ, Zwart JA (2007) The global burden of headache: a documentation of headache prevalence and disability worldwide. Cephalalgia 27:193-210

19. World Health Organization (2000) WHO report on Headache. Headache Australia, September 2000. http://www.headacheaustralia. org.au/?p=70. Accessed 16 Dec 2007

20. Mutuja WBP, Mteza LBH, Rwiza HT (1995) Headaches in a nonclinical Population in Dares salaam, Tanzania. A communitybased study Headache 35:273-276

21. Aids for management of common headache disorders in primary care (2007) J Headache Pain 8(S1):1-47 